Sir,

\title{
Corniced Wind Scoops
}

Mr. S. Bland, one of the observers in the Society's Snow Survey, sends details of twin wind scoops which he watched in process of formation around his two-storeyed house and the garage at Ongar, Essex.

The wind producing the scoops was rotating anticlockwise around the garage and clockwise around the house. There is a well near the south corner of the garden with brickwork projecting $18 \mathrm{in}$. $(46 \mathrm{~cm}$.) above ground and from this a ridge of snow built up in a curve towards the cusp between the two scoops. Each eddy had a vortical motion which caused cornices $3 \mathrm{ft} .6 \mathrm{in}$. (107 cm). high overhanging about $2 \mathrm{ft}$. $(6 \mathrm{r} \mathrm{cm}$.) at the cusp. The cornice at the point of the cusp gradually advanced towards the ridge of snow from the well. At the same time a spray of fine, powdery snow, blowing from the roof of the cornice, was building up this ridge as the cusp advanced. The wind was force 6 to 7 with gusts above gale force.

The points of special interest are, first, that all the observed wind effects were at right angles to the direction one would have expected them to take, and second, the effect of the well head in modifying the shape of the "tail" of the scoop around the garage. Both effects must be due to the wind having been funnelled through the openings in the hedges as shown by the arrows in the diagram below.
14 Stanmore Road,
London N.r 5 .

28 February 1948

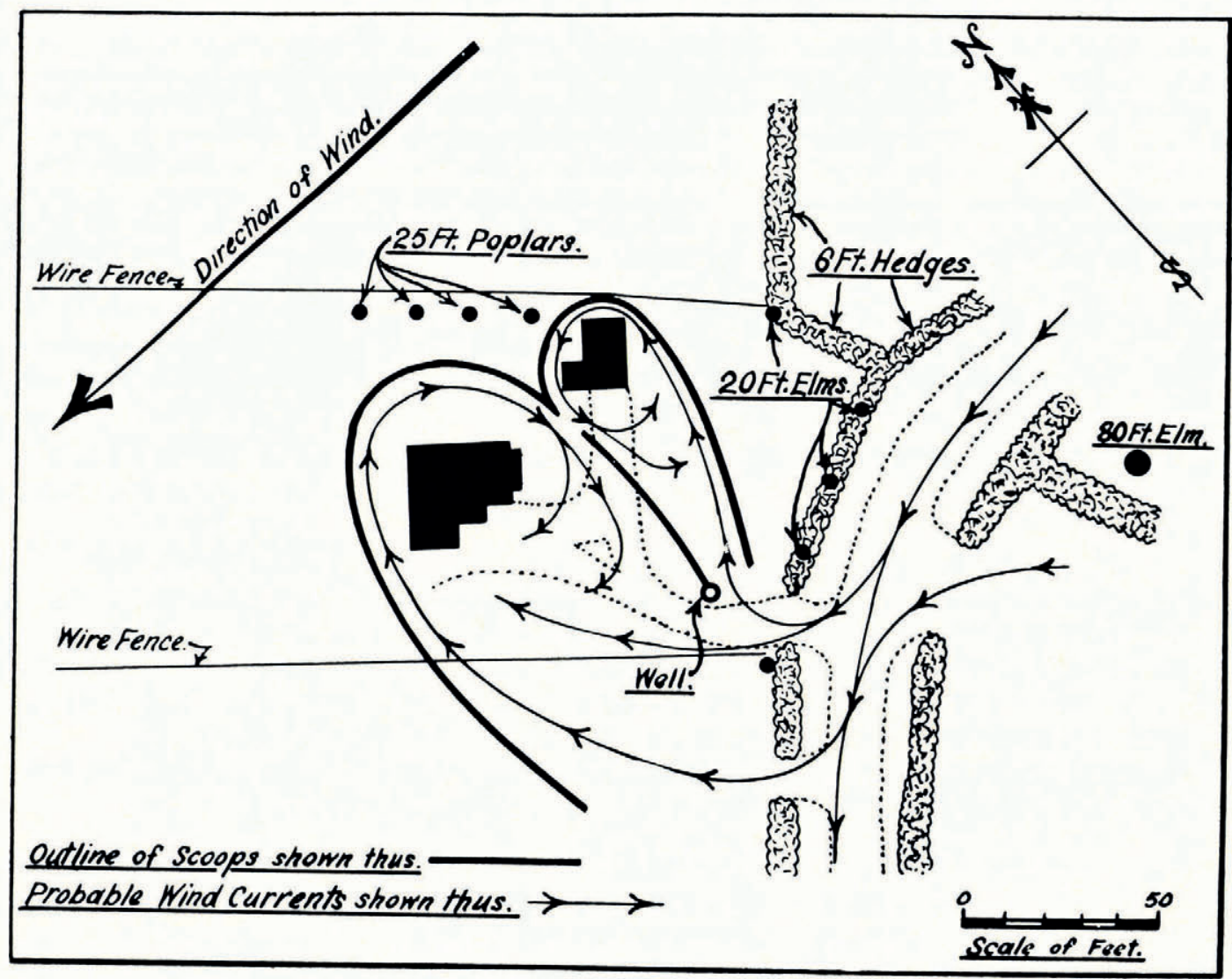

